Technological University Dublin ARROW@TU Dublin

\title{
Rapid fabrication of silver nanoparticle/polydopamine functionalized polyester fibers
}

\author{
Yanfen Zhou \\ Qingdao University \\ Liang Jiang \\ Qingdao University \\ Ya Guo \\ Qingdao University
}

See next page for additional authors

Follow this and additional works at: https://arrow.tudublin.ie/cerart

Part of the Polymer and Organic Materials Commons

\section{Recommended Citation}

Zhou, Y., Jiang, L., Guo, Y., Sun, Z., Jiang, Z., Chen, S., Ma, J., \& Jerrams, S. (2019). Rapid fabrication of silver nanoparticle/polydopamine functionalized polyester fibers. Textile Research Journal, 89(19-20), 3968-3978. DOI: 10.1177/0040517519826893

This Article is brought to you for free and open access by the Centre for Elastomer Research at ARROW@TU Dublin. It has been accepted for inclusion in Articles by an authorized administrator of ARROW@TU Dublin. For more information, please contact arrow.admin@tudublin.ie, aisling.coyne@tudublin.ie,gerard.connolly@tudublin.ie. Funder: National Natural Science Foundation of China; Natural Science Foundation of Shandong Province; Key Research and Development Program of Shandong Province 


\section{Authors}

Yanfen Zhou, Liang Jiang, Ya Guo, Zhenhua Sun, Zhiqing Jiang, Shaojuan Chen, Jianwei Ma, and Stephen Jerrams 


\title{
Rapid fabrication of silver nanoparticle/polydopamine functionalized polyester fibers
}

Textile Research Journal 2019, Vol. 89(19-20) 3968-3978 (C) The Author(s) 2019 Article reuse guidelines: sagepub.com/journals-permissions DOI: $10.1177 / 0040517519826893$ journals.sagepub.com/home/trj

SAGE

\author{
Yanfen Zhou',2, Liang Jiang ${ }^{1,2}{ }^{10}$, Ya Guo', Zhenhua Sun', \\ Zhiqing Jiang', Shaojuan Chen', Jianwei $\mathrm{Ma}^{\mathrm{l,2}}$ and \\ Stephen Jerrams ${ }^{3}$
}

\begin{abstract}
In this paper, silver nanoparticles functionalized poly(ethylene terephthalate) (PET) fibers with antimicrobial activity, electrical conductivity and good coating stability are reported. Firstly, silver plated PET fibers were fabricated by rapid polydopamine (PDA) modification followed by electroless plating. Secondly, the surface morphologies and compositions of PDA modified and silver coated PET fibers were characterized by employing scanning electron microscopy, atomic force microscopy, X-ray diffraction and energy dispersive spectrometry. Finally, the antimicrobial properties and electrical conductivity of the silver plated PET fibers were investigated. The results showed that the silver coated PET fibers exhibited excellent antimicrobial activity to both Escherichia coli and Staphylococcus aureus (with an antimicrobial efficiency of 100 and $99.99 \%$, respectively), and that the antimicrobial activity was well maintained after washing. The silver coated PET fibers showed electrical resistance of $0.76 \Omega$ per I cm, indicating good conductivity. It was also demonstrated that the silver layer that formed had good mechanical durability, as indicated by conductivity measurements during tensile loading and observation of the surface morphology of the fibers under various modes of deformation.
\end{abstract}

\section{Keywords}

PET fibers, polydopamine, silver nanoparticles, antimicrobial, electrical conductivity

Fibers functionalized with silver nanoparticles are attracting an increasing amount of interest since they can be used in various applications including conductive shields, electronic sensors, electromagnetic interference shielding and antibacterial textiles. ${ }^{1-5}$ Commonly used methods to produce metal coated materials include sputtering methods, ${ }^{6}$ electroplating, ${ }^{7}$ in situ synthesis, ${ }^{2,8}$ electroless plating ${ }^{9,10}$ and self-assembly. ${ }^{11}$ Among these methods, electroless plating is the most widely used in industry due to its advantages of being a simple procedure together with achieving a continuous and uniform coating layer. ${ }^{12}$ However, the disadvantages of the electroless plating method are that it requires careful control of the plating bath composition $^{13}$ and requires an activation step for the substrates in order to produce catalytic sites for the deposition of metals. Conventionally, substrate fibers are processed either by $\operatorname{tin}(\mathrm{II})$ chloride $\left(\mathrm{SnCl}_{2}\right)$ sensitization followed by palladium(II) chloride $\left(\mathrm{PdCl}_{2}\right)$ activation, or by silane modification. ${ }^{14,15}$ However, the problems of multistep procedures include a significant requirement for instruments and toxic solvents involved in these processes, which limit their wide application.

In recent years, inspired by the adhesion mechanism of mussels, dopamine (DA) has been widely used as an excellent material candidate for surface modification

\footnotetext{
'School of Textiles and Clothing, Qingdao University, China

${ }^{2}$ Industrial Research Institute of Nonwovens and Technical Textiles, Qingdao University, China

${ }^{3}$ Centre for Elastomer Research, Dublin Institute of Technology, Ireland

Corresponding author:

Liang Jiang, School of Textiles and Clothing, Qingdao University, China. Email: majianwei1959@gmail.com
} 
due to several advantages of simple ingredients, mild reaction conditions and general applicability to various types of substrate materials. ${ }^{4,16-20}$ The method of polydopamine (PDA) modification has also been used for the preparation of silver coated fibers. ${ }^{1,21-25}$ For example, Wang et al. ${ }^{23,24}$ prepared silver functionalized poly(ethylene terephthalate) (PET) fibers and polymetaphenylene isophthamide (PMIA) fibers with PDA modification followed by electroless plating. The results showed that both silver coated PET and PMIA fibers exhibited good electrical conductivity (with surface resistivities of 0.40 and $0.61 \mathrm{~m} \Omega \cdot \mathrm{cm}$, respectively), and satisfactory stability was achieved by ultrasonic treatment. $\mathrm{Hu}$ et al. ${ }^{25}$ prepared conductive ultrahigh-molecular weight polyethylene fibers by employing PDA modification followed by electroless silver plating. The resistance of the silver coated fibers was measured at $0.15 \Omega / \mathrm{cm}$ per bundle. However, it should be noted that in these research projects, the PDA modification process generally took $24 \mathrm{~h}$, which is very time-consuming. It is known that the formation of PDA was associated with oxidation, intra-molecular cyclization and rearrangement, followed by multistep reactions that lead to deposited thin film on the material's surface. ${ }^{16}$ The initial DA oxidation reaction is critical to initiate thin-film deposition on a material surface, but this process is very slow in air conditions. ${ }^{26}$ It has been demonstrated that the formation of PDA can be accelerated to some extent by employing various oxidizing agents, such as ammonium persulfate, sodium periodate and copper ions. ${ }^{27,28}$ However, to date there has been no report on the preparation of silver coated fibers by combining rapid PDA modification and electroless plating.

The applications of silver coated fibers are largely dependent on their conductivity ${ }^{1}$ and antimicrobial properties. ${ }^{29}$ The mechanical durability of the silver nanoparticles is also of great importance as silver coated fibers are inevitably subjected to external forces in service or when further processed (e.g. by spinning, weaving or knitting). However, research into silver coated fibers to date has mainly focused on their conductivity and antimicrobial properties, and investigation of mechanical durability has largely been ignored.

Based on these considerations, in this work, silver coated PET fibers were prepared by employing rapid DA modification followed by electroless plating. The DA modification process was accelerated by using $\mathrm{CuSO}_{4} / \mathrm{H}_{2} \mathrm{O}_{2}$. The coated silver layer was characterized using Fourier transform infrared spectroscopy (FTIR), scanning electron microscopy (SEM), atomic force microscopy (AFM), X-ray diffraction (XRD) and energy dispersive spectrometry (EDS). Antimicrobial activity against Escherichia coli and Staphylococcus aureus, as well as the change of electrical conductivity during tensile loading of the silver coated fibers, were investigated. In particular, the coating durability of the deposited silver nanoparticles subjected to mechanical loading was evaluated.

\section{Methods/experimental}

\section{Materials}

PET fibers used in the present study were commercial multifilament yarns having $1500 / 136 / 0$ specification, i.e. 1500 denier, 136 filaments and zero twist. The fibers were supplied by Zhengfeng Braid Co., Ltd, Jiangxi, China. The PET fibers were ultrasonically cleaned with ethanol and hydrochloric acid followed by distilled water to remove surface contaminants, and then vacuum dried before use. DA hydrochloride (DA.HCl) and tris (hydroxymethyl) aminomethane (Tris) were procured from Macklin, China; silver nitrate $\left(\mathrm{AgNO}_{3}\right)$ was purchased from the Shanghai Fine Chemicals Research Institute; and copper sulfate $\left(\mathrm{CuSO}_{4} \cdot 5 \mathrm{H}_{2} \mathrm{O}\right)$, hydrogen peroxide $\left(\mathrm{H}_{2} \mathrm{O}_{2}\right)$, ammonia $\left(\mathrm{NH}_{3} \cdot \mathrm{H}_{2} \mathrm{O}\right)$, glucose, ethanol and distilled water were supplied by Qingdao Shengtianyi Chemical Plant, China and used without further treatment.

\section{PDA modification of PET fibers}

Initially, a DA solution with a concentration of $2.0 \mathrm{~g} / \mathrm{L}$ was prepared by dissolving $\mathrm{DA} \cdot \mathrm{HCl}$ powder in distilled water and the $\mathrm{pH}$ value of the solution was adjusted to 8.5 by adding Tris. $\mathrm{CuSO}_{4}$ and $\mathrm{H}_{2} \mathrm{O}_{2}$ were added to the DA solution with a concentration of $1.8 \mathrm{~g} / \mathrm{L}$ and $0.6 \mathrm{ml} /$ $\mathrm{L}$, respectively. PET fibers were then put in the DA/ $\mathrm{CuSO}_{4} / \mathrm{H}_{2} \mathrm{O}_{2}$ solution and processed at $25^{\circ} \mathrm{C}$ for $1 \mathrm{~h}$. After treatment, PET fibers were separated from the solution, rinsed three times with distilled water and then dried in a vacuum oven at $60^{\circ} \mathrm{C}$ overnight. Pristine PET fibers and PDA treated PET fibers were referred to as PET and PET/PDA, respectively.

\section{Electroless deposition of silver on PET/PDA}

Silver nitrate solution with a concentration of $8 \mathrm{~g} / \mathrm{L}$ was prepared by dissolving $4 \mathrm{~g}$ silver nitrate in $500 \mathrm{~mL}$ distilled water; ammonia solution at a concentration of $50 \mathrm{~mL} / \mathrm{L}$ was then added slowly to the silver nitrate solution whilst stirring until the solution became transparent. PET/PDA fibers were put in the prepared solution, and then glucose solution (with a concentration of $12 \mathrm{~g} / \mathrm{L}$ ) was dripped slowly into the above mixture to initiate the reduction of silver. After reaction under magnetic stirring for $2 \mathrm{~h}$, the fibers were separated, washed thoroughly with distilled water and dried in a 
vacuum oven at $60^{\circ} \mathrm{C}$ overnight. The fibers obtained were referred to as PET/PDA/Ag. A schematic illustration of the surface modification, and the silver coating process for PET fibers and the corresponding reaction mechanism are depicted in Figure 1.

\section{Characterization}

The surface functional groups of the PDA modified PET fibers were characterized using FTIR (Nicolet iS5, USA), and spectra were recorded in the attenuated total reflectance mode. The surface morphology of PET fibers was observed by using SEM (Phenom Pro, Netherlands). Samples were coated with a fine layer of gold $(2 \mathrm{~nm})$ before undergoing observation. Images with different magnifications were taken at an accelerating voltage of $5 \mathrm{kV}$. The diameters of 100 individual particles were measured by using Image J software, and the particle size distribution and average particle size were obtained based on the individual measurements. The crystalline structure of the silver coated PET fibers was investigated by XRD (Bruker D8 Advance, Germany); $\mathrm{Cu} \mathrm{K} \alpha$ radiation with a wavelength of $1.54056 \AA$ was used, and the diffraction patterns were recorded from 10 to $80^{\circ}$. Surface element compositions of PET and PET/ PDA/Ag fibers were analyzed using EDS (INCAxSight6427, Oxford).

The durability of silver nanoparticles against washing was determined by conducting ultrasonic washing and standard washing cycles according to the International Organization for Standardization standard ISO $105 \mathrm{C} 01$. For ultrasonic washing, the PET/ PDA/Ag fibers were washed in deionized water under ultrasonication (with a power of $2500 \mathrm{~W}$ and frequency of $28 \mathrm{kHz}$ ) for $1 \mathrm{~h}$ at $25^{\circ} \mathrm{C}$, then dried in vacuum oven at $60^{\circ} \mathrm{C}$ overnight and used for further testing. For standard washing, a water-resistant colorfastness tester (SW 20B, Meibang Instrument, Quanzhou, China) was used. Specifically, a certain amount of PET/PDA/Ag fibers were placed in the sample cup ( $550 \mathrm{ml}$ volume) and a standard soap solution pre-heated to $40^{\circ} \mathrm{C}$ was added at a concentration of $5 \mathrm{~g} / \mathrm{L}$, and the bath ratio was controlled at 50:1. The fibers were washed for five cycles, and for a single washing cycle the washing condition was set at $40^{\circ} \mathrm{C}$ for $30 \mathrm{~min}$ with the sample cup rotating at $40 \mathrm{r} / \mathrm{min}$. After washing three times with distilled water, PET/PDA/Ag fibers were dried in a vacuum oven at $60^{\circ} \mathrm{C}$ overnight and used for further testing.

Antimicrobial activities of pristine PET fibers, silver coated PET fibers and silver coated PET fibers after washing were tested against E. coli (AATCC 11229) and $S$. aureus (AATCC 6538). The antimicrobial experiments were conducted according to the agar diffusion plate method (GB/T 20944.1-2007) and the shake flask method (GB/T 20944.3-2008). The agar diffusion plate method provides qualitative data (known as the inhibition zone) for measuring the antibacterial activity of silver coated fibers, while the shake flask

(a)

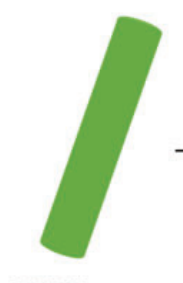

PET fiber

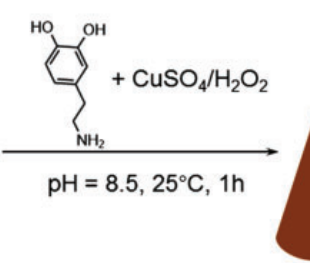

PET/PDA fiber (b) $\mathrm{H}_{2} \mathrm{O}_{2}+\mathrm{HO}^{-} \longleftrightarrow \mathrm{HO}_{2}^{-}+\mathrm{H}_{2} \mathrm{O}$

$\mathrm{Cu}^{2+}+\mathrm{HO}_{2}^{-}+3 \mathrm{OH}^{-} \leftrightarrow \mathrm{O}_{2} \mathrm{Cu}(\mathrm{OH})_{2}^{2-}+\mathrm{H}_{2} \mathrm{O}$

$\mathrm{Cu}^{2+}+\mathrm{H}_{2} \mathrm{O}_{2}+3 \mathrm{OH}^{-} \longleftrightarrow \mathrm{HO}_{2} \mathrm{Cu}(\mathrm{OH})_{2}{ }^{-}+\mathrm{H}_{2} \mathrm{O}$

$\left.\mathrm{Cu}^{2+}+3 \mathrm{OH}^{-} \longleftrightarrow \mathrm{Cu}(\mathrm{OH})_{3}\right)^{-}$

$\mathrm{Cu}^{2+}+4 \mathrm{OH}^{-} \leftrightarrow \mathrm{Cu}(\mathrm{OH})_{4}^{2-}$

$\mathrm{O}_{2} \mathrm{Cu}(\mathrm{OH})_{2}{ }^{2-} \longleftrightarrow \mathrm{Cu}(\mathrm{OH})_{2}{ }^{-}+\mathrm{O}_{2}{ }^{*}$

$\mathrm{HO}_{2} \mathrm{Cu}(\mathrm{OH})_{2}{ }^{-} \leftrightarrow \mathrm{Cu}(\mathrm{OH})_{2}{ }^{-}+\mathrm{HO}_{2}{ }^{*}$

$\mathrm{Cu}(\mathrm{OH})_{2}{ }^{-}+\mathrm{O}_{2}+\mathrm{OH}^{-} \longleftrightarrow \mathrm{Cu}(\mathrm{OH})_{3}{ }^{-}+\mathrm{O}_{2}{ }^{-}$

$\mathrm{Cu}(\mathrm{OH})_{2}{ }^{-}+\mathrm{H}_{2} \mathrm{O}_{2} \longleftrightarrow \mathrm{Cu}(\mathrm{OH})_{3}{ }^{-}+\mathrm{OH}^{*}$

$\mathrm{Cu}(\mathrm{OH})_{2}{ }^{-}+\mathrm{HO}_{2}^{-} \longleftrightarrow \mathrm{Cu}(\mathrm{OH})_{3}{ }^{-}+\mathrm{OH}^{*}+\mathrm{OH}^{-}$

$\mathrm{OH}^{*}+\mathrm{H}_{2} \mathrm{O}_{2} \longleftrightarrow \mathrm{H}_{2} \mathrm{O}+\mathrm{HO}_{2} \cdot$

$\mathrm{OH}^{*}+\mathrm{HO}_{2} \longrightarrow \mathrm{H}_{2} \mathrm{O}+\mathrm{O}_{2} \cdot-$

$\mathrm{R}+\mathrm{R} \leftrightarrow \mathrm{H}_{2} \mathrm{O}_{2}\left(\mathrm{HO}_{2}{ }^{-}\right)+\mathrm{O}_{2}\left(+\mathrm{OH}^{-}\right) \quad\left(\mathrm{R}=\mathrm{HO}_{2}{ }^{*}+\mathrm{O}_{2}{ }^{*}\right)$ (c)

$\mathrm{AgNO}_{3} / \mathrm{NH}_{3} \cdot \mathrm{H}_{2} \mathrm{O}+$ glucose

$25^{\circ} \mathrm{C}, 2 \mathrm{~h}$

PET/PDA/Ag fiber

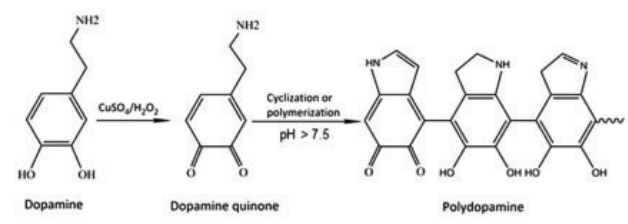

Polydopamine

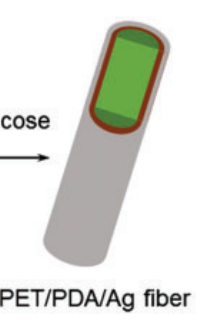


method gives quantitative data for antimicrobial efficiency, which can be calculated by using equation (1)

$$
Y=\frac{W_{t}-Q_{t}}{W_{t}}
$$

where $Y$ is the antimicrobial efficiency, and $W_{t}$ and $Q_{t}$ represent the live bacteria concentrations before and after contact with the specimen for $18 \mathrm{~h}$, respectively.

Tensile properties and the change in electrical conductivity during tensile loading of the silver coated PET fibers were measured by using a modified tensile testing machine for fibers. A digital multimeter was connected between the two grips of the tensile testing machine. Hence, the change of electrical resistance was recorded during in situ tensile loading. Test conditions were as follows: a pre-load of $10 \mathrm{cN}$ was applied for a separation rate of $100 \mathrm{~mm} / \mathrm{min}$ for a gauge length of $100 \mathrm{~mm}$ at a temperature of $20^{\circ} \mathrm{C}$ and relative humidity of $65 \%$. In order to investigate the mechanical stability of the coated silver layer, PET/PDA/Ag fibers were subjected to various degrees of deformation and different times of cyclic loading at a constant displacement of 0 to $5 \mathrm{~mm}$ at a speed of $100 \mathrm{~mm} / \mathrm{min}$, and then the surface morphologies of $\mathrm{PET} / \mathrm{PDA} / \mathrm{Ag}$ fibers were observed utilizing SEM.

\section{Results and discussion}

\section{Effect of $\mathrm{CuSO}_{4} / \mathrm{H}_{2} \mathrm{O}_{2}$ on the $\mathrm{DA}$ reaction}

The formation mechanism of DA-inspired thin-film deposition in the presence of oxidants and in alkaline conditions is related to the oxidative polymerization of DA. ${ }^{31}$ The DA oxidation reaction resulted in a solution that turned from clear and transparent to dark brown and opaque as the reaction proceeded to completion. ${ }^{26}$ Figure 2(a) shows the color changes of DA and $\mathrm{DA} / \mathrm{CuSO}_{4} / \mathrm{H}_{2} \mathrm{O}_{2}$ solutions with reaction time. Figure 2(b) is a plot of UV/Vis (ultraviolet/visible light) absorbance at $420 \mathrm{~nm}$, which is a characteristic peak of PDA, ${ }^{28}$ with reaction times for DA and DA/ $\mathrm{CuSO}_{4} / \mathrm{H}_{2} \mathrm{O}_{2}$. It can be seen that the solution of DA was initially pink and gradually changed to be cloudy when the reaction time reached $60 \mathrm{~min}$. In contrast, the solution of $\mathrm{DA} / \mathrm{CuSO}_{4} / \mathrm{H}_{2} \mathrm{O}_{2}$ was a yellowy brown at the beginning and then turned dark brown within $30 \mathrm{~min}$, indicating more rapid formation of PDA. This is because $\mathrm{CuSO}_{4}$ acted to oxidize DA, while in alkaline conditions, $\mathrm{CuSO}_{4} / \mathrm{H}_{2} \mathrm{O}_{2}$ produced a large number of reactive oxygen species including $\mathrm{O}_{2}{ }^{-}$, $\mathrm{HO}_{2}$. and $\mathrm{OH} \cdot{ }^{30}$ which triggered the polymerization of DA and improve the deposition rate of PDA on the substrates. ${ }^{28}$

Figure 2(b) shows the $\mathrm{UV} / \mathrm{Vis}$ absorbances at $420 \mathrm{~nm}$ of the DA and $\mathrm{DA} / \mathrm{CuSO}_{4} / \mathrm{H}_{2} \mathrm{O}_{2}$ solutions after they were diluted three times. It is shown that the absorbance of $\mathrm{DA} / \mathrm{CuSO}_{4} / \mathrm{H}_{2} \mathrm{O}_{2}$ was much higher than that of DA at each reaction time. After polymerization for $60 \mathrm{~min}$, the absorbance of $\mathrm{DA} / \mathrm{CuSO}_{4} / \mathrm{H}_{2} \mathrm{O}_{2}$ reached 2.43, which was much higher than that of DA at 0.328 . Therefore, it was confirmed that the polymerization of DA can be accelerated by the introduction of $\mathrm{CuSO}_{4} / \mathrm{H}_{2} \mathrm{O}_{2}$.

\section{FTIR analysis}

The surface color of the PET fibers changed from white to dark brown after PDA modification, as shown in Figure 3(a). FTIR was employed to analyze the change of functional groups of PET fibers before and after PDA modification, and the results are

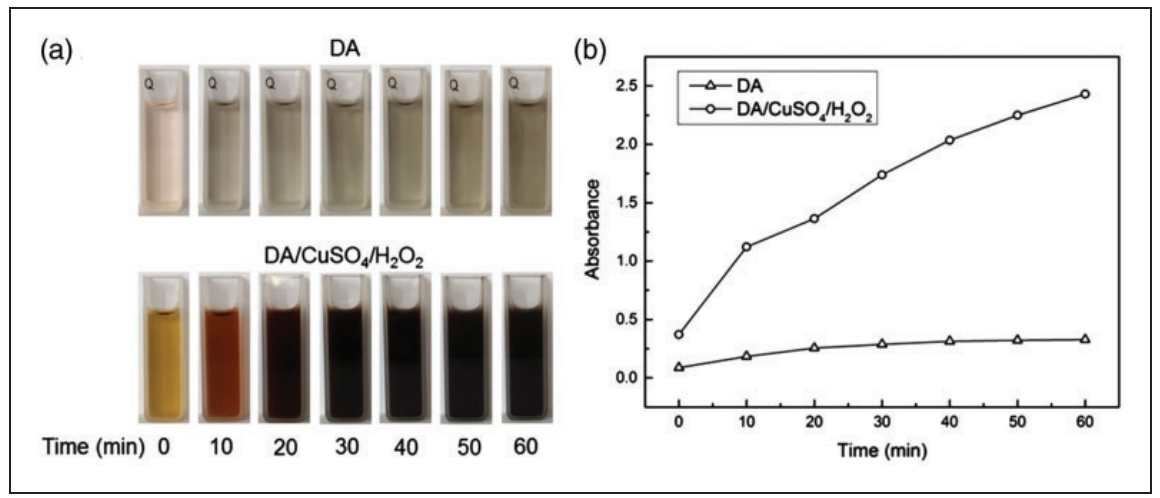

Figure 2. (a) Color change and (b) ultraviolet/visible light absorbance at $420 \mathrm{~nm}$ with reaction time for dopamine and dopamine/ $\mathrm{CuSO}_{4} / \mathrm{H}_{2} \mathrm{O}_{2}$; the ultraviolet/visible light absorbance of dopamine and dopamine/CuSO$/ \mathrm{H}_{2} \mathrm{O}_{2}$ was measured after the solution was diluted three times.

DA: dopamine. 


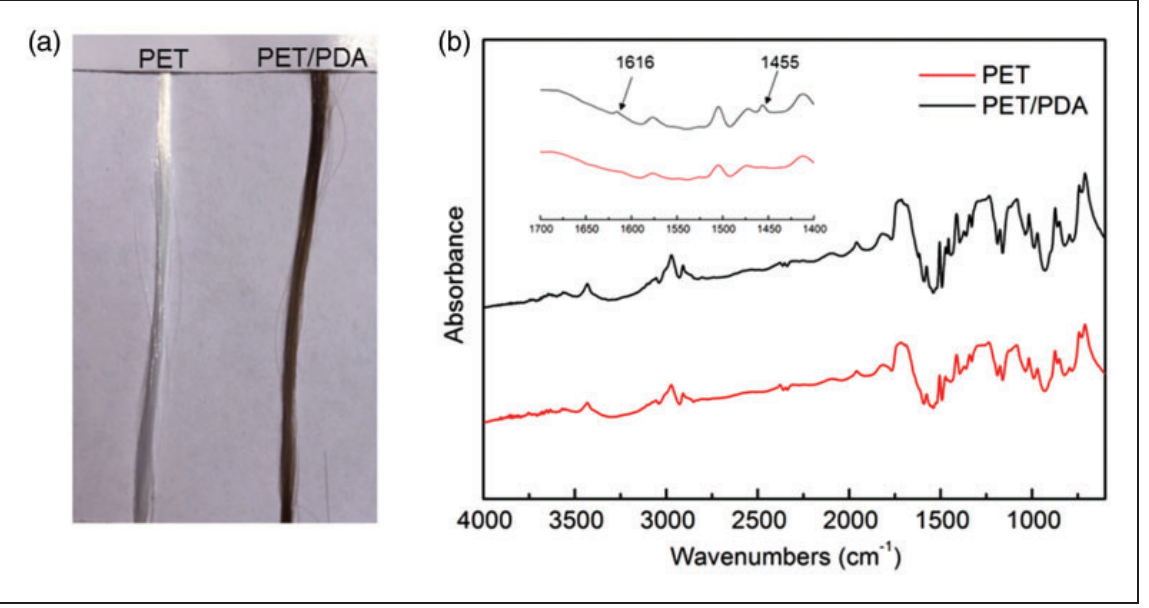

Figure 3. (a) Digital image and (b) Fourier transform infrared spectra of poly(ethylene terephthalate) and poly(ethylene terephthalate)/polydopamine fibers.

PDA: polydopamine; PET: poly(ethylene terephthalate).

shown in Figure 3(b). It can be seen that both PET fibers and PET/PDA fibers exhibited peaks at 1720 ( $\mathrm{O}=\mathrm{C}-\mathrm{O}$ group), 2965 (C-H asymmetric in the $\mathrm{CH}$ and $\mathrm{CH}_{2}$ groups of the benzene ring $), 1410\left(\mathrm{CH}_{2}\right.$ scissor vibration) and $1230 \mathrm{~cm}^{-1}$ (C-O stretching vibration). Besides, some new peaks were shown in the spectra of PDA modified PET fibers. The band at $1455 \mathrm{~cm}^{-1}$ was assigned to the $\mathrm{C}-\mathrm{N}$ stretching of PDA, ${ }^{32}$ while the absorbance at $1616 \mathrm{~cm}^{-1}$ was ascribed to the $\mathrm{C}=\mathrm{C}$ stretching vibration of indole in PDA. ${ }^{33}$ The weak absorbance intensity of these peaks might be due to the low thickness of the PDA layer. These results prove the successful immobilization of the PDA layer on the surface of PET fibers.

\section{Surface morphology}

The surface morphologies of three categories of PET fibers, including untreated, PDA modified and silver coated, are shown in Figure 4. It can be seen from Figure 4(a) that the surface of pristine PET fibers was smooth. In contrast, a layer of PDA can be seen on the surface of PET fibers after PDA treatment (Figure 4(b)). After silver plating, the silver particles were clearly observed as shown in Figure 4(c). The average particle size $\left(D_{a}\right)$ was measured at 208 with an SD $(\sigma)$ of $29 \mathrm{~nm}$. AFM was used to analyze the surface morphology of PET, PET/PDA and PET/ $\mathrm{PDA} / \mathrm{Ag}$ fibers, and the resultant three-dimensional images are shown in Figure 4(d) to (f). The surface of pristine PET fibers was relatively smooth with a surface roughness $\left(R_{a}\right)$ of $1.55 \mathrm{~nm}$. Gullies were observed on PET/PDA fibers with a surface roughness of $4.92 \mathrm{~nm}$ and this implies the successful modification of the fibers. The surface of PET/PDA/Ag fibers was much coarser with a surface roughness of $16.3 \mathrm{~nm}$ occurring on the deposited silver nanoparticles.

\section{Surface composition}

XRD and EDS were employed to further confirm the deposition of silver particles on the surface of PET fibers. XRD patterns for pristine PET fibers and silver coated PET fibers are presented in Figure 5(a). Compared with pristine fibers, the diffracted intensity of the peaks for silver coated fibers located between $2 \theta$ of 14 and $28^{\circ}$, which were the crystal faces of PET fibers, weakened significantly because of the plating of silver particles on the fiber surface. New peaks at $2 \theta=38.3,44.5,64.9$ and $77.8^{\circ}$ were found in the XRD pattern of silver plated PET fibers. These peaks can be assigned to the (111), (200), (220) and (311) planes of the cubic structure of metallic $\mathrm{Ag},{ }^{19}$ revealing the formation of face-centered cubic silver crystallite on the surface of PET fibers. No diffraction peaks corresponding to silver halide or silver oxide were observed in the XRD patterns of silver coated PET fibers, indicating that the silver particles deposited on the PET fiber surface were in the metallic state.

Element composition of PET fibers and PET/PDA/ Ag fibers was determined using EDS, and the results are shown in Figure 5(b) and (c), respectively. It can be seen that the pristine PET fiber was composed of $\mathrm{C}$ and $\mathrm{O}$ elements with a carbon to oxygen signal ratio $(\mathrm{C} / \mathrm{O})$ of 1.966, which is close to the theoretical value of 1.875 for the $\mathrm{C} / \mathrm{O}$ ratio for PET. The EDS spectrum for PET/ PDA/Ag fibers in Figure 5(c) shows that the content of $\mathrm{Ag}$ is $88.9 \mathrm{wt} \%$, and, meanwhile, the signals for $\mathrm{C}$ and $\mathrm{O}$ were markedly weakened because of the deposition of a dense silver layer on the surfaces of PET fibers. 


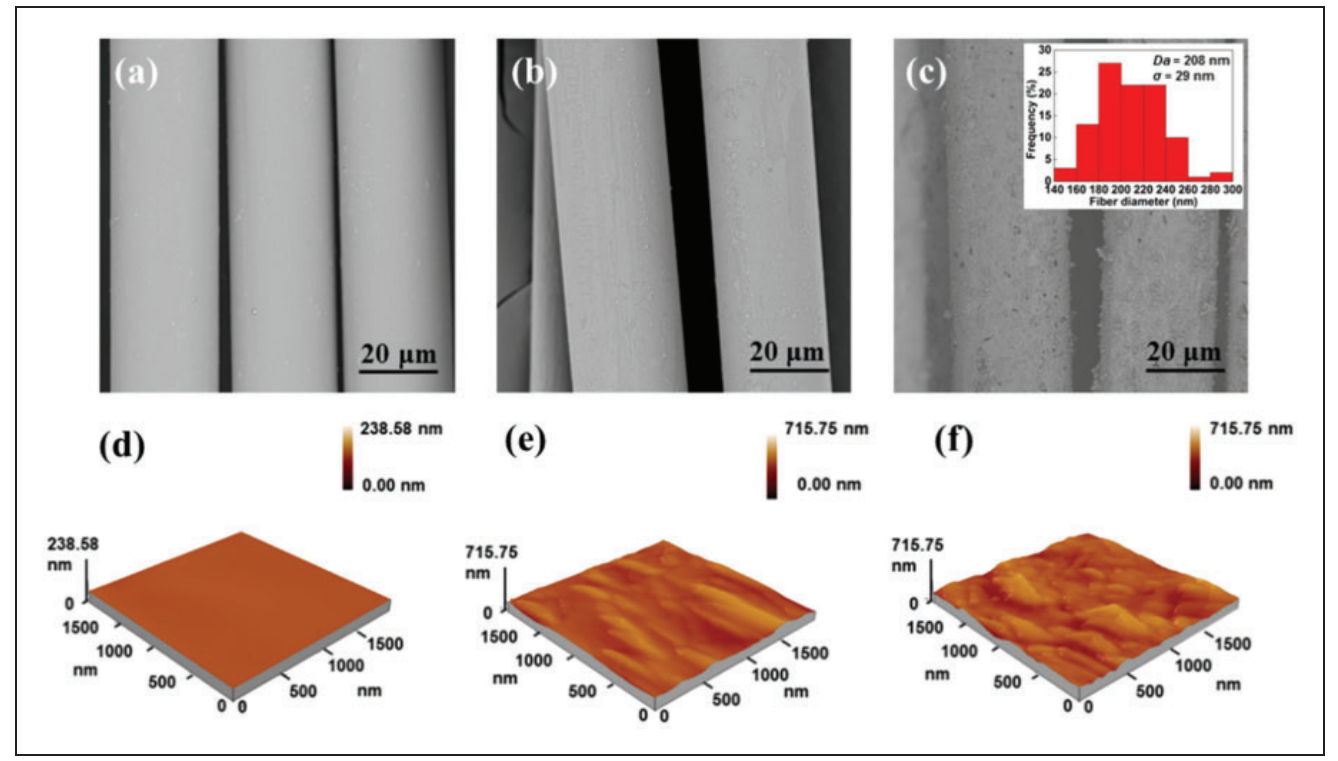

Figure 4. Scanning electron microscopy images of (a) pristine poly(ethylene terephthalate) fibers, (b) poly(ethylene terephthalate)/ polydopamine fibers and (c) poly(ethylene terephthalate)/polydopamine/Ag fibers, and (d) atomic force microscopy profile of pristine poly(ethylene terephthalate) fibers, (e) poly(ethylene terephthalate)/polydopamine fibers and (f) poly(ethylene terephthalate)/polydopamine/Ag fibers.

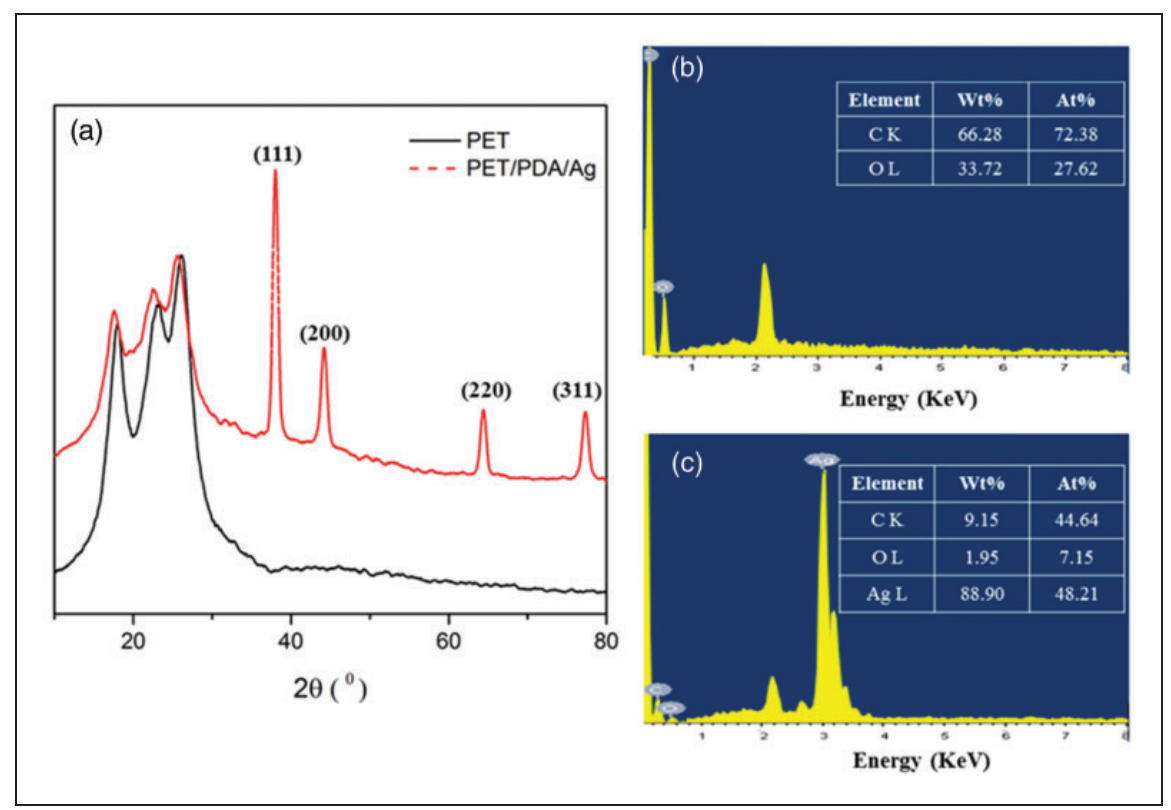

Figure 5. (a) X-ray diffraction of poly(ethylene terephthalate) fibers and poly(ethylene terephthalate)/polydopamine/Ag fibers. (b) Energy dispersive spectrometry spectra of poly(ethylene terephthalate) fibers and (c) poly(ethylene terephthalate)/ polydopamine/Ag fibers.

PDA: polydopamine; PET: poly(ethylene terephthalate).

\section{Antimicrobial properties}

Figure 6 demonstrates the results of the inhibition zone used to evaluate the antimicrobial activity against $E$. coli and $S$. aureus of various PET fibers. It can be observed from Figure 6(a), (b), (f) and (g) that the samples of pristine PET fibers and PET/PDA fibers failed to show an inhibition zone, indicating no antimicrobial features against $E$. coli and $S$. aureus. However, a clear inhibition zone was observed for the sample of silver 


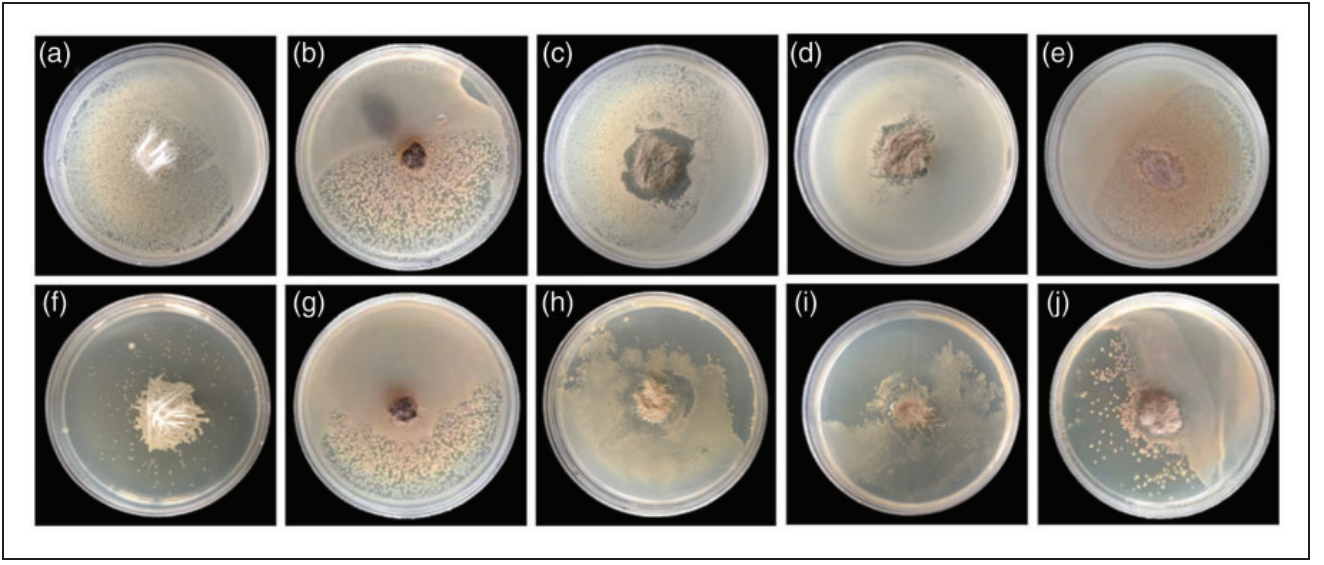

Figure 6. Antimicrobial ring tests for poly(ethylene terephthalate), poly(ethylene terephthalate)/polydopamine and poly(ethylene terephthalate)/polydopamine/Ag fibers. (a)-(e) Antimicrobial rings against $E$. coli: (a) poly(ethylene terephthalate) fibers,

(b) poly(ethylene terephthalate)/polydopamine fibers, (c) poly(ethylene terephthalate)/polydopamine/Ag fibers, (d) ultrasonic washed poly(ethylene terephthalate)/polydopamine/Ag fibers and (e) poly(ethylene terephthalate)/polydopamine/Ag fibers after standard washing for five cycles. (f)-(j) antimicrobial rings against S. aureus: (f) poly(ethylene terephthalate) fibers, ( $g$ ) poly (ethylene terephthalate)/polydopamine fibers, (h) poly(ethylene terephthalate)/polydopamine/Ag fibers, (i) ultrasonic washed poly (ethylene terephthalate)/polydopamine/Ag fibers and (j) poly(ethylene terephthalate)/polydopamine/Ag fibers after standard washing for 5 cycles.

plated PET fibers against both E. coli and S. aureus, as shown in Figure 6(c) and (h). The widths of the inhibition zones were measured to be 2.8 and $3.6 \mathrm{~mm}$ for $E$. coli and S. aureus, respectively. The silver nanoparticles appeared to have broken the cell wall of the microorganism and attacked the respiration chain and cell division, which finally led to cell death. ${ }^{34}$ As shown in Figure 6(d), (i), (e) and (g), silver coated PET fibers still exhibited obvious antimicrobial action against $E$. coli and $S$. aureus after ultrasonic and standard washing, though the decrease in the growth inhibition rings $(1.2$ and $1.1 \mathrm{~mm}$ in width for $E$. coli and 1.4 and $1.3 \mathrm{~mm}$ in width for $S$. aureus, respectively) might have been caused by the decrease in antimicrobial activity.

The antimicrobial efficiency of silver coated PET fibers before and after washing was measured, and the results are shown in Figure 7. It was found that the antimicrobial efficiency of PET/PDA/Ag fibers reached $100 \%$ against E. coli and $99.99 \%$ against $S$. aureus, respectively. After washing in water under ultrasonication for $1 \mathrm{~h}$, the antimicrobial efficiency against $E$. coli and $S$. aureus slightly dropped to 98.2 and $97.8 \%$, respectively. The antimicrobial efficiency against $E$. coli and $S$. aureus was 97.6 and $97.2 \%$ after standard washing for five cycles. The results suggest that the silver coated PET fibers have high antimicrobial activity against both $E$. coli and $S$. aureus, and that their antimicrobial activity can be well maintained even after various washing treatments.

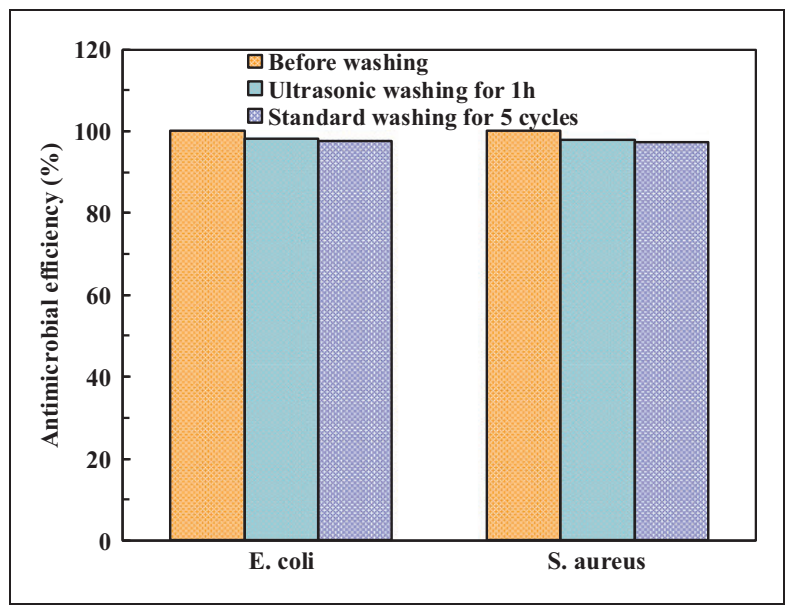

Figure 7. Antibacterial efficiency tests for poly(ethylene terephthalate)/polydopamine/Ag fibers.

\section{Conductivity and mechanical stability of PET/PDA/Ag fibers}

The electrical resistance of PET/PDA/Ag fibers measured by a two-point multimeter was $0.76 \Omega$ over a length of $1 \mathrm{~cm}$, indicating good conductivity after deposition of silver nanoparticles. After standard washing for five cycles, the electrical resistance of $\mathrm{PET} / \mathrm{PDA} / \mathrm{Ag}$ fibers increased to $1.78 \Omega$ over a length of $1 \mathrm{~cm}$, which also indicates good stability against washing of the coated silver nanoparticles. 


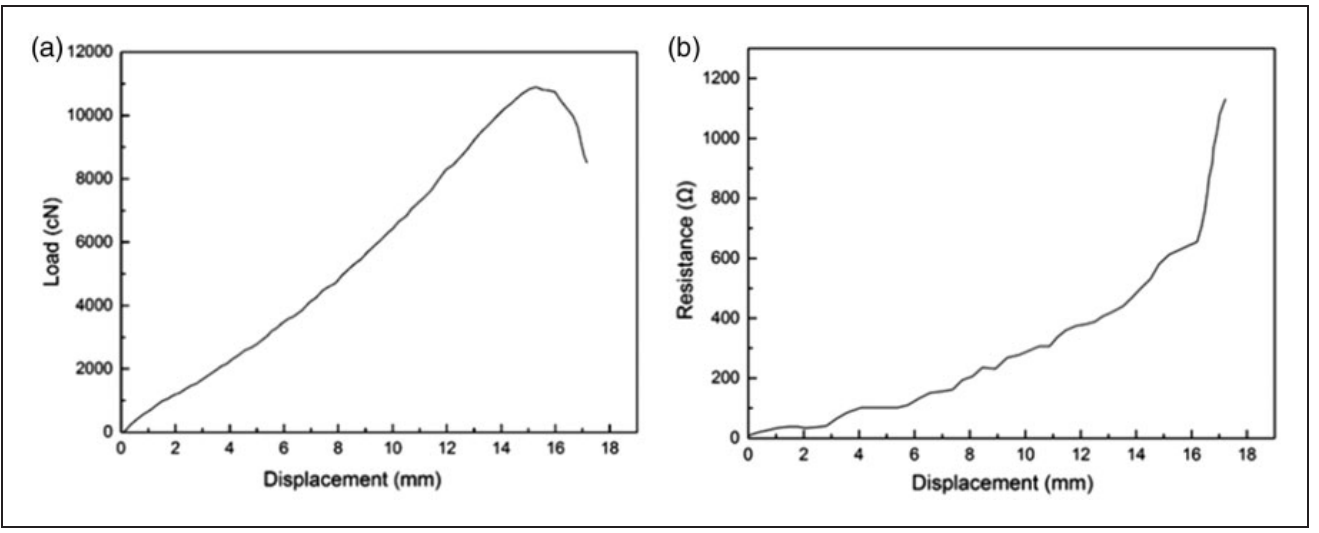

Figure 8. (a) Load-displacement curve and (b) change of resistance versus displacement for poly(ethylene terephthalate)/polydopamine/Ag fibers.

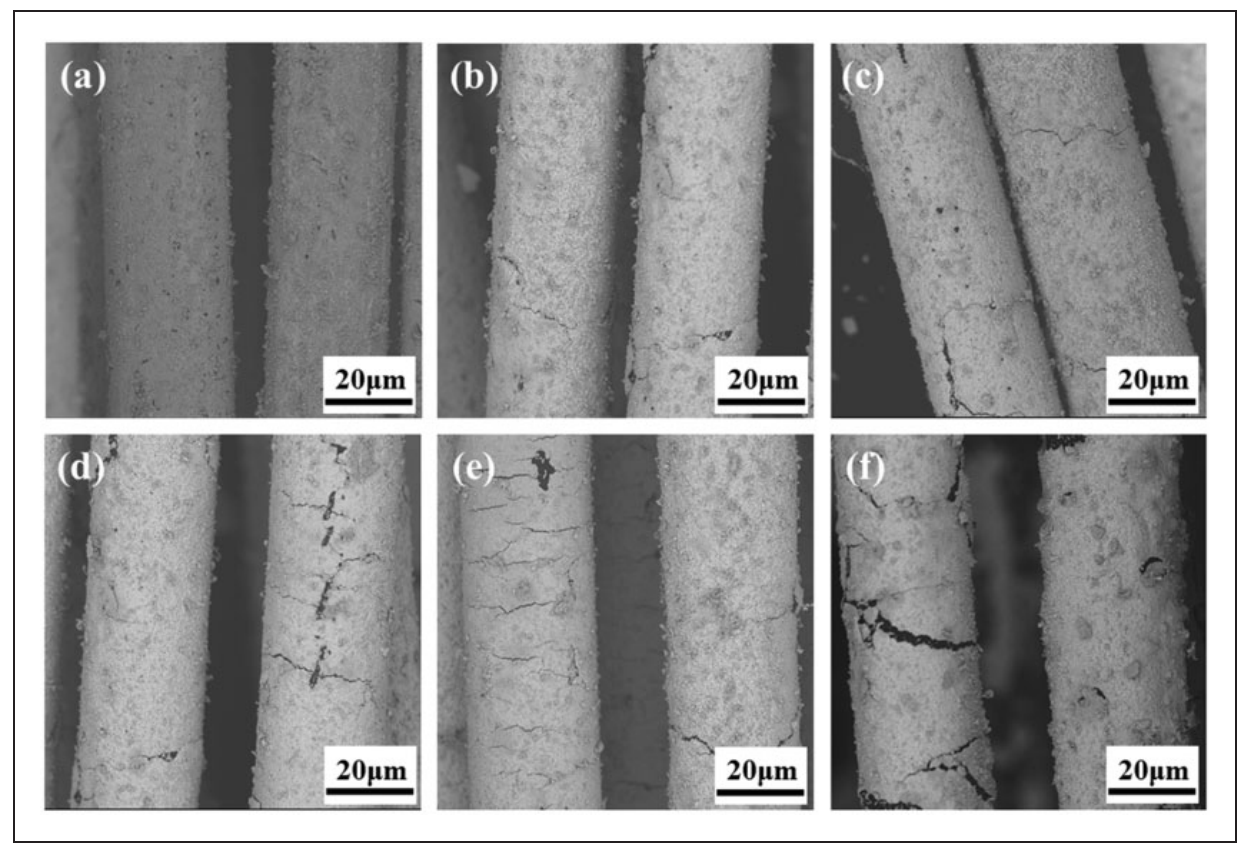

Figure 9. Scanning electron microscopy images of (a) pristine poly(ethylene terephthalate)/polydopamine/Ag fibers and poly(ethylene terephthalate)/polydopamine/Ag fibers at different displacement; (b) 3, (c) 5, (d) 10 and (e) 15 mm, and (f) at tensile break.

Figure 8 shows a typical load displacement curve and the change of electrical resistance versus displacement for PET/PDA $/ \mathrm{Ag}$ fibers. It can be seen from Figure 8(b) that the electrical resistance increased with increasing displacement until tensile failure occurred, indicating decreased conductivity with fiber elongation. The increase in resistance can be due to two effects: firstly, as the fibers were elongated, the length increased and the cross-sectional area decreased, hence the resistance increased as in compliance with equation (2); secondly, as the fibers were stretched, the coated silver layers were subjected to increasing damage, which also led to an increase in electrical resistance.

$$
R=\rho \cdot \frac{l}{S}
$$

where $R$ is the resistance in $\Omega, \rho$ is the resistivity in $\Omega \cdot \mathrm{m}$, $l$ is the length in $\mathrm{m}$ and $S$ is the cross-sectional area in $\mathrm{m}^{2}$. The average value of resistance just before failure was $1130 \Omega$, which suggests that the silver coated fibers still had a certain degree of conductivity prior to tensile failure. 


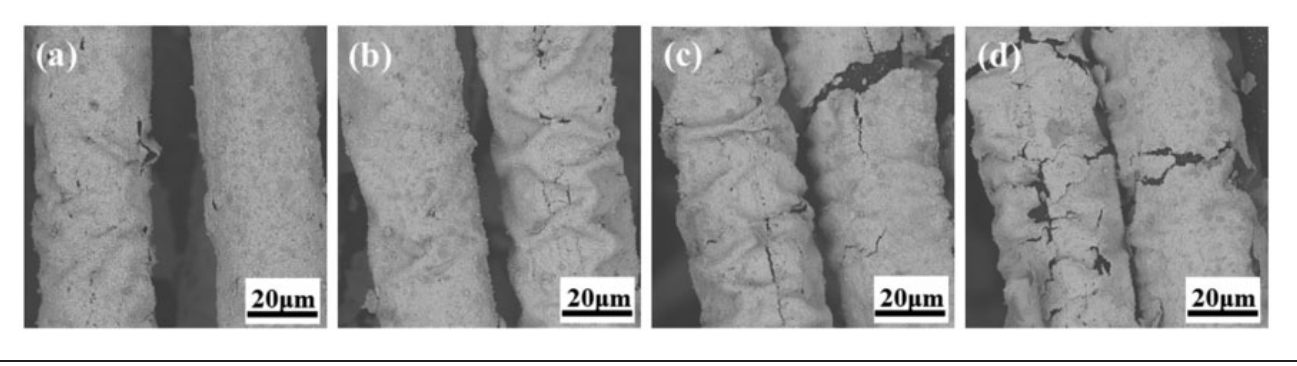

Figure I0. Scanning electron microscopy images of poly(ethylene terephthalate)/polydopamine/Ag fibers after different numbers of loading cycles: (a) 10, (b) 30, (c) 50 and (d) 100 cycles; displacement was kept at 0-5 mm.

In order to investigate the mechanical durability of the coated silver layer, PET/PDA/Ag fibers were stretched to various degrees of deformation, and the surface morphologies of the stretched fibers were observed by using SEM as depicted in Figure 9. Compared with the original silver coated PET fibers, the surfaces of PET/PDA/Ag fibers experienced different stretching and showed various degrees of damage in the form of cracks and exfoliation. In particular, for the fibers subjected to low deformations ( 3 and $5 \mathrm{~mm}$ ), only cracks were seen on the fiber surfaces. With the increase in displacement, both the numbers and the sizes of the cracks in the silver coating increased, and some small exfoliations can be clearly seen on the surfaces of the fibers (Figure 9(d) and (e)). However, the silver layer did not exhibit any peeling even at tensile failure as shown in Figure 9(f), implying that the binding force between the coated silver layer and PDA modified PET fibers was strong.

Surface morphologies of PET/PDA/Ag fibers subjected to different times of cyclic loading at a constant displacement of 0 to $5 \mathrm{~mm}$ were also assessed to further investigate the mechanical stability of the coated silver layer. As shown in Figure 10, with the increase in cyclic loading, wrinkles can be clearly seen on the surface of PET/PDA/ $\mathrm{Ag}$ fibers besides small cracks and small exfoliations. As the fibers were stretched, provided that the coated silver layer deformed along with the fibers, the adhesion between the fibers and the coated silver layers was not destroyed. However, due to the differences between the deformation recovery abilities between the PET fibers and the silver layer, some of the silver nanoparticles separated from the fiber surfaces and wrinkles formed after specific cycles of deformation. Although a certain number of cracks and exfoliations appeared on the surface of silver coated fibers after 100 cycles, most of the silver nanoparticles were still attached to the fiber surface, indicating good mechanical stability of the coated silver layers.

\section{Conclusions}

Silver coated PET fibers were prepared through PDA modification and electroless plating. The deposition rate of PDA on the fiber surface was significantly improved by using $\mathrm{CuSO}_{4} / \mathrm{H}_{2} \mathrm{O}_{2}$ as an oxidants and trigger. The silver coated fibers exhibited excellent antimicrobial activity against both $E$. coli and $S$. aureus, and the antimicrobial performance was well maintained after washing. The silver coated PET fibers also showed good conductivity with a resistance of $0.76 \Omega$ per $1 \mathrm{~cm}$. The coated silver layer was found to have good mechanical durability, as indicated by electrical conductivity measurements during tensile loading and surface morphology observation of the fibers after various degrees of deformation. Combing the characteristics of excellent antimicrobial properties, good electrical conductivity and robust coating durability, the silver coated PET fibers are expected to be good candidate materials for the production of functional fabrics and nonwovens, which can be used in the fields of healthcare and smart wearables.

\section{Acknowledgements}

We would like to express our sincere gratitude to the National Natural Science Foundation of China (grant no. 51703108), the Natural Science Foundation of Shandong Province, China (grant no. ZR2017BEM042) and the Key Research and Development Program of Shandong Province, China (grant No. 2018GGX108003) for their financial support.

\section{Declaration of conflicting interests}

The authors declared no potential conflicts of interest with respect to the research, authorship and/or publication of this article.

\section{Funding}

The authors received no financial support for the research, authorship and/or publication of this article.

\section{ORCID iD}

Liang Jiang (D) http://orcid.org/0000-0002-7792-6069

\section{References}

1. Liu H, Zhu LL, He Y, et al. A novel method for fabricating elastic conductive polyurethane filaments by in-situ 
reduction of polydopamine and electroless silver plating. Mater Des 2017; 113: 254-263.

2. Pivec T, Hribernik S, Kolar M, et al. Environmentally friendly procedure for in-situ coating of regenerated cellulose fibres with silver nanoparticles. Carbohyd Polym 2017; 163: 92-100.

3. Rehan M, Barhoum A, Van Assche G, et al. Towards multifunctional cellulosic fabric: UV photo-reduction and in-situ synthesis of silver nanoparticles into cellulose fabrics. Int J Biol Macromol 2017; 98: 877-886.

4. Lu S, Yu J, Cheng Y, et al. Preparation of silver nanoparticles/polydopamine functionalized polyacrylonitrile fiber paper and its catalytic activity for the reduction 4-nitrophenol. Appl Surf Sci 2017; 411: 163-169.

5. Wang C, Xiang C, Tan L, et al. Preparation of silver/ reduced graphene oxide coated polyester fabric for electromagnetic interference shielding. $R S C A d v$ 2017; 7: 40452-40461.

6. Jiang SX, Qin WF, Guo RH, et al. Surface functionalization of nanostructured silver-coated polyester fabric by magnetron sputtering. Surf Coat Technol 2010; 204: 3662-3667.

7. Bilger C, Bruck HA and Dasgupta A. Electroplated connections between carbon fiber and nickel. J Electron Packag 2017; 139: 011009.

8. GhavamiNejad A, Rajan Unnithan A, Ramachandra Kurup Sasikala A, et al. Mussel-inspired electrospun nanofibers functionalized with size-controlled silver nanoparticles for wound dressing application. ACS Appl Mater Interfaces 2015; 7: 12176-12183.

9. Liao F, Han XR, Zhang YF, et al. Carbon fabrics coated with nickel film through alkaline electroless plating technique. Mater Lett 2017; 205: 165-168.

10. Nam YW, Choi JH, Lee WJ, et al. Fabrication of a thin and lightweight microwave absorber containing Ni-coated glass fibers by electroless plating. Compos Sci Technol 2017; 145: 165-172.

11. Zhou LF, Yuan L, Guan QB, et al. Building unique surface structure on aramid fibers through a green layer-by-layer self-assembly technique to develop new high performance fibers with greatly improved surface activity, thermal resistance, mechanical properties and UV resistance. Appl Surf Sci 2017; 411: 34-45.

12. Xu C, Zhou R, Chen H, et al. Silver-coated glass fibers prepared by a simple electroless plating technique. J Mater Sci-Mater Electron 2014; 25: 4638-4642.

13. Vasconcelos B, Vediappan K, Oliveira JC, et al. Mechanically robust silver coatings prepared by electroless plating on thermoplastic polyurethane. Appl Surf Sci 2018; 443: 39-47.

14. Lili L, Dan Y, Le W, et al. Electroless silver plating on the PET fabrics modified with 3-mercaptopropyltriethoxysilane. $J$ Appl Polym Sci 2012; 124: 1912-1918.

15. Wang W, Li W, Gao C, et al. A novel preparation of silver-plated polyacrylonitrile fibers functionalized with antibacterial and electromagnetic shielding properties. Appl Surf Sci 2015; 342: 120-126.
16. Lee H, Dellatore SM, Miller WM, et al. Mussel-inspired surface chemistry for multifunctional coatings. Science 2007; 318: 426-430.

17. Wang L, Hu L, Gao S, et al. Bio-inspired polydopaminecoated clay and its thermo-oxidative stabilization mechanism for styrene butadiene rubber. $R S C A d v$ 2015; 5: 9314-9324.

18. Wang L, Shi YX, Sa RN, et al. Surface modification of aramid fibers by catechol/polyamine codeposition followed by silane grafting for enhanced interfacial adhesion to rubber matrix. Ind Eng Chem Res 2016; 55: 12547-12556.

19. Yi M, Sun $H$, Zhang $H$, et al. Flexible fiberreinforced composites with improved interfacial adhesion by mussel-inspired polydopamine and poly (methyl methacrylate) coating. Mater Sci Eng $C$ 2016; 58: 742-749.

20. Peng L, Guo R, Lan J, et al. Microwave-assisted deposition of silver nanoparticles on bamboo pulp fabric through dopamine functionalization. Appl Surf Sci 2016; 386: 151-159.

21. Hu J, Feng X, Liu Z, et al. Surface amine-functionalization of UHMWPE fiber by bio-inspired polydopamine and grafted hexamethylene diamine. Surf Interface Anal 2017; 49: 640-646.

22. Fu Y, Liu L, Zhang L, et al. Highly conductive onedimensional nanofibers: Silvered electrospun silica nanofibers via poly(dopamine) functionalization. ACS Appl Mater Interfaces 2014; 6: 5105-5112.

23. Wang W, Cheng $\mathrm{W}$, Tian $\mathrm{M}$, et al. Preparation of PET/Ag hybrid fibers via a biomimetic surface functionalization method. Electrochim Acta 2012; 79: 37-45.

24. Wang W, Li R, Tian M, et al. Surface silverized metaaramid fibers prepared by bio-inspired poly(dopamine) functionalization. ACS Appl Mater Interfaces 2013; 5: 2062-2069.

25. Hu W, Zeng Z, Wang Z, et al. Facile fabrication of conductive ultrahigh molecular weight polyethylene fibers via mussel-inspired deposition. J Appl Polym Sci 2013; 128: 1030-1035.

26. Kim HW, McCloskey BD, Choi TH, et al. Oxygen concentration control of dopamine-induced high uniformity surface coating chemistry. ACS Appl Mater Interfaces 2013; 5: 233-238.

27. Hong SH, Hong S, Ryou MH, et al. Sprayable ultrafast polydopamine surface modifications. Adv Mater Interfaces 2016; 3: 1500857.

28. Zhang C, Ou Y, Lei WX, et al. CuSO4/H2O2-induced rapid deposition of polydopamine coatings with high uniformity and enhanced stability. Angew Chem Int Ed 2016; 128: 3106-3109.

29. Wang R, Shin CH, Park S, et al. Enhanced antibacterial activity of silver-coated Kapok fibers through dopamine functionalization. Water Air Soil Pollut 2014; 226: 2241

30. Luo Y, Orban M, Kustin K, et al. Mechanistic study of oscillations and bistability in the 
copper(II)-catalyzed reaction between hydrogen peroxide and potassium thiocyanate. J Am Chem Soc 1989; 111: 4541-4548.

31. Liu XS, Cao JM, Li H, et al. Mussel-inspired polydopamine: A biocompatible and ultrastable coating for nanoparticles in vivo. ACS Nano 2013; 7: 9384-9395.

32. Li X, Shan H, Cao M, et al. Mussel-inspired modification of PTFE membranes in a miscible THF-Tris buffer mixture for oil-in-water emulsions separation. $J \mathrm{Membr}$ Sci 2018; 555: 237-249.

33. Knorr DB, Tran NT, Gaskell KJ, et al. Synthesis and characterization of aminopropyltriethoxysilane-polydopamine coatings. Langmuir 2016; 32: 4370-4381.

34. Zhang S, Tang YG and Vlahovic B. A review on preparation and applications of silver-containing nanofibers. Nanoscale Res Lett 2016; 11: 8. 